\title{
Erratum: "Study of the Optical Variability of T Tau in the Period 1962-2003" [Astron. Lett. 31 (2), 109 (2005)]
}

\section{S. Yu. Mel'nikov and K. N. Grankin}

There was a misprint in the final pages (in both the Russian and English versions): Instead of October 5 , 1999, the text should have read September 5, 1999 (see the description in the text and the caption to Fig. 2). 